\title{
Applying Neural Networks in Case-Based Reasoning Adaptation for Cost Assessment of Steel Buildings
}

\author{
Essam Amin M. Lotfy, M.Sc. \\ Products Resaerch \& Development \\ Zamil Steel Building Co. Egypt \\ 30 St. 270 New Maddi, Cairo \\ Ahmed Sameh Mohamed, Ph.D. \\ Departement of Computer Science \\ The American University in Cairo \\ 113 Kasr El Aini St., Cairo 11511 Egypt
}

\begin{abstract}
In is paper, a new technique in complex adaptation is investigated. By presenting the closest retrieved cases to a neural network, it learns about the domain of the problem being solved. The new problem is then fed to the trained neural network and the output becomes the solution to that problem. The methodology is applied to a problem in the steel construction and the sought output is the cost estimation of pre-engineered steel buildings.Several experiments are conducted to prove that these steps are successful. System verification is done and shows that both the system and the methodology are successful to develop a complete adaptation mechanism in CBR.
\end{abstract}

Keywords: Case-Based Reasoning, Case Adaptation, Complex Case Adaptation, Neural Networks

executed projects could be captured, stored and reused as a part of the estimation process, many estimation problems could be solved more easily and accurately. This information does not contain general knowledge. It is instead created to be valid for a specific design situation. This kind of information is termed cases. The rational way to use old design cases when solving a new design problem is the case-based reasoning and is the aim of this paper. This paper has dual objectives. The first is investigating the feasibility of integrating neural networks with case-based reasoning to come up with strong knowledge-intensive model of complex adaptation. The second is building a CBR system that assists steel contractors in developing fast and accurate cost estimates for new projects.

The next two sections deal with Pre-Engineered steel buildings, CBR, and Neural Networks. After a section with the technical description of system development, the followed sections are mainly implementation issues treating all the CBR issues. Then the section on result evaluation discusses the obtained results. Finally the evaluation of the system and the conclusion sections judge whether the system has been successful in marrying CBR and Neural Networks with the PreEngineered building cost estimation. full design and bill of material of the building before they win the bid. So they make cost estimation of the building based on their own experience in previous buildings. If the building cost is underestimated, a construction enterprise may suffer a tremendous loss and eventually fail. If the information about the previously

\footnotetext{
${ }^{1}$ Pre-engineered buildings are parameterized buildings with known architectural shapes. Customers need to fill these parameters to get an appropriate building that fits their needs.
}

\section{The Pre-Engineered Steel Buildings}

Although, they are pre-engineered, Pre-Engineered buildings need a lengthy design process to accurately calculate all of their component material. The ultimate requirement of this lengthy design process is to produce 
safe and economic building. To produce a safe design is so easy. One should apply the design code equations to get safe dimensions of a building. However, economic design of a building encounters a very important aspect called shape optimization. Figure 1 illustrates four alternate shapes of one Pre-Engineered steel building.

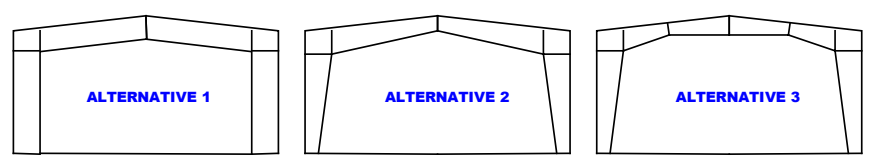

Figure 1: Four Alternative Shapes of One P.E.B.

Because the stress variation in the main structural element, frames can take several shapes. A good design is the one that produces a safe frame with as minimum weight as possible. To do it, one engineer may perform several trials with full calculations, and that is why the process of designing a building might take weeks or months even with the use of computer-aided design software (CAD).

Most of the Pre-Engineered steel buildings have some similarities in their parameters, and design engineers have calculated them in many cases over and over again. If the information about previously executed projects could be captured, stored and reused as a natural part of the estimation process, the cost assessment will be done easily and accurately. Much of the information about old projects is available in the large contracting companies whether in hardcopy or in electronic databases. For example, Zamil Steel Building Co. has a database of previously executed projects, which has over 8000 records. So it will be appropriate if this data is collected and converted into a case-base to allow automated cost estimation systems.

\section{Domain Analysis \& Case Representation}

Each building in our model is considered a case. Cases can be represented in a variety of forms using the full range of data representation. An object-oriented model is selected to represent the cases.

A major advantage of object-oriented model is the use of one-to-one mapping between the model and the real world objects. So, for a Pre-Engineered steel building, the key class is the building itself as shown in the class diagram. Other classes can be divided into three categories.

Building sub-systems category includes roof monitors, fascias, roof extensions, expansion joints, and canopies. Building accessories category includes doors, windows, ventilators, and louvers. Additional systems category includes cranes and mezzanines. One more class, which does not belong to the previous categories, is the loads acting on the building.
A major relationship in the Pre-Engineered steel building domain is the "Has" relationship. The domain has one aggregate class that owns other classes. The owner class is the client class and the owned class is the supplier class.

Defining attributes that describe different classes is considered simple task if the classes are similar to real world classes. For example the class building has width, length, height, and roof slope. These real parameters will be attributes in the class building. All other classes will be cured in the same manner.

\section{Data Acquisition}

Much of the effort in building a case-based system goes into case collection. If it is impossible or especially difficult to collect cases, then case based reasoning will be too difficult, or impossible, to apply.

Cases need to be collected according to the needs of the system, that is, based on its goals. Cases in the case library should provide as much coverage as possible about achieving reasoning goals. The first pass at building a case library is often unlikely to provide full coverage. So refinement of this pass is required to achieve the required coverage (Kolodner, 1993).

Fortunately, the available data from Zamil Steel projects is adequate to build good case library of the PreEngineered steel building. The actual case-base is refined and a case-base consists of 480 cases of real projects is built.

\subsection{Assigning Importance Values to Case Features}

The weight assigned to each feature of the case tells how much attention to pay to matches and mismatches in the field when computing the distance measure of a case. One way to assign importance values is to have a human expert assign them as the case library is being built. The expert might have some feeling about which dimension and

combinations of dimensions make good predictors

(Kolodner, 1993). Another way to assign importance

values is to do a

statistical

evaluation of a

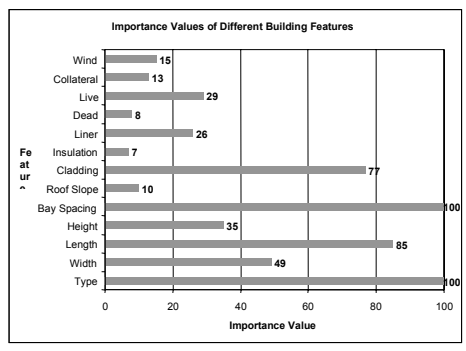

Figure 2: Importance Values of Building Features

known corpus

of cases to determine which dimension predicts different outcomes and/or solutions best. Those that are good predictors are then assigned higher importance for 
matching (Kolodner, 1993). Both methods are applied to assign importance values to different features in the case-base.

Figure 2 illustrates the assigned values of the different building features. The figure reflects the experience and the statistical study of the different parameters. The figure shows that 'Bay-Spacing' and 'Type' are the most important features. Following these features are the 'Length' and 'Cladding'. 'Dead' and 'Insulation' have the least importance over all values.

\section{Case Indexing \& Retereival}

The intended CBR system is about to suggest an accurate cost estimation for a new steel building, given all the building attributes. The assumption underlying case-based reasoning is that, if the building attributes of two different buildings are similar, their cost should be similar. In fact, this is seldom to be done in the steel building domain because of the wide variations of the Pre-Engineered building attributes. Instead, several closest match cases should be retrieved and adapted. The system's accuracy, precision, speed, and efficiency thus depend on its ability to recall a set of cases that are significantly similar to the new problem case.

Figure 3 shows the results of the distance measure between the 480 cases and one query case. The numbers in the $\mathrm{X}$-axis is just a serial number of the cases and the Y-axis represents the distance measure. Cases are sorted according to the distance measure.

\section{Case Adaptation}

As illustrated above the Pre-

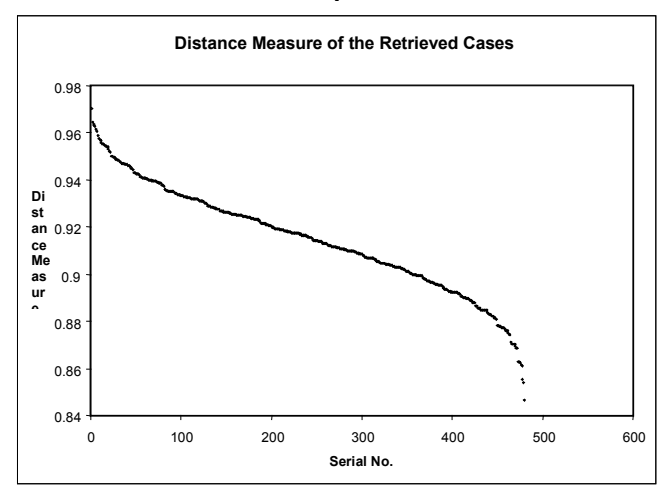

Fimure 2. Mictanne Meacure of the Retrieved Cacac two partial solutions are composed to make the final solution.

Neural computing applications are usually designed and optimized using an iterative approach (try- adjust- try again). Therefore, the initial design task is a starting point for an iterative process of design refinements. Its result is not a single design but a set of design options together with a specifications for the experiments intended to resolve the competing design issues.

After the iterative process, the used neural network has one input layer with 11 units, two hidden layers, the first has 5 units, the second has 4 units, and one output unit. All activation functions are sigmoid, and the network is fully interconnected. The learning rate $(\eta)$ ranges from 0.15 to 0.25 , and the momentum $(\alpha)$ equals to 0.5 .

\subsection{Training the Neural Network}

On-line training is used to deal with changing conditions. Since the retrieved cases change with time, on-line training or periodic retaining of specialized architectures is necessary. Two important points are taken into account during the installation of the on-line training.

The first point is the stability of the training algorithm. No sudden changes in the weights of the neural network have been discovered. In each experiment, the network is initialized and it converges at the end of the experiment with almost the same root mean square error. Therefore, there is no significant risk from the on-line training. This is because the closeness of the input patterns. These patterns are all close to one case that is the query case. In ordinary networks, data may include diverse of input patterns that may cause sudden change in weights during the training.

The second point is that the online training may be very expensive, costly, and too slow to respond to the users. All experiments are done on ordinary personal computer. The response time for all experiments ranges from 15 to 60 minutes. The response time here is considered fast response with respect to the manual cost estimation system. This manual system takes about two to three working days to complete the estimation of an ordinary Zamil Steel project.

\subsection{Main Building Experiments}

The following four experiments illustrate the neural network training which is conducted for eleven input parameters described above and 30 cases for each query. Because building type and roof slope are constant for all fed into a neural network to get its solution. Finally, the 
selected buildings, they are execluded from the threteen features showd in figure 2. Table 1 illustrates the network parameters and training results.

Table 1: Main Building Experiments Training Results

\begin{tabular}{|l|l|l|l|l|}
\hline & $(\mathrm{A})$ & $(\mathrm{B})$ & $(\mathrm{C})$ & $(\mathrm{D})$ \\
\hline Input units & 11 & 11 & 11 & 11 \\
Hidden Layers & $2(5,4)$ & $2(5,4)$ & $2(5,4)$ & $2(5,4)$ \\
Output Unit & 1 & 1 & 1 & 1 \\
Learning rate $(\eta)$ & $0.25-0.15$ & $0.25-0.15$ & $0.25-0.15$ & $0.25-0.15$ \\
Momentum $(\alpha)$ & 0.5 & 0.5 & 0.5 & 0.5 \\
Activation Functions & Sigmoid & Sigmoid & Sigmoid & Sigmoid \\
Epoch Length & 30 & 30 & 30 & 30 \\
Iterations & 125120 & 253305 & 248480 & 240000 \\
\hline Root Mean Square & 0.00256 & 0.0032 & 0.0034 & 0.00247 \\
Error (RMS) & 0.001 & 0.001 & 0.001 & 0.001 \\
Target RMS: & & & & \\
\hline
\end{tabular}

\subsubsection{Experiment (E) Complex Case Adaptation}

In this experiment, The mezzanine system is separated from its building to generate two other sub-problems: the building system and the mezzanine system. Two techniques are applied incremental-CBR (Cunningham, et al., 1998) in the case retrieval and decomposition for the case adaptation. The incremental CBR mechanism can initiate case retrieval with a structural case description that is used to retrieve a matching subset of the case-base. This is done here as the mezzanine system can query the case-base and retrieve a subset of the mezzanine cases, and so the building system does. As the decomposition technique, described above, is applied, the two sets of cases are then fed into two neural networks. Table 2 illustrates the network parameters and training results for the decomposed system into main building and a mezzanine system.

Table 2: Experiment (E) Training Results

\begin{tabular}{|l|l|l|}
\hline & Main Building & Mezzanine \\
\hline Input units & 11 & 6 \\
Hidden Layers & $2(5,4)$ & $2(3,2)$ \\
Output Unit & 1 & 1 \\
Learning rate $(\eta)$ & $0.25-0.18$ & $0.25-0.15$ \\
Momentum $(\alpha)$ & 0.5 & 0.5 \\
Activation Functions & Sigmoid & Sigmoid \\
Epoch Length & 30 & 30 \\
Iterations & 425820 & 47105 \\
\hline Root Mean Square & 0.003 & 0.002 \\
Error (RMS) & 0.001 & 0.001 \\
Target RMS & & \\
\hline
\end{tabular}

\subsection{Testing the Neural Network}

For the testing task, post-processing of the neural network output is required. Post-processing is done the opposite way the pre-processing is done. The neural output is decoded by multiplying the output with the cost of the reference case. This gives back the cost of the solution. Table 3 illustrates the testing results of the five experiments.

Table 3: Neural Network Results

\begin{tabular}{|c|c|c|c|c|c|}
\hline Exper & A & $\mathrm{B}$ & $\mathrm{C}$ & & \\
\hline & $\begin{array}{l}\text { Buildin } \\
\text { g Cost }\end{array}$ & 89329 & 1363900 & 2402380 & 74464 \\
\hline CBR & $\begin{array}{l}\text { Retriev } \\
\text { ed Cost }\end{array}$ & 75693 & 1421148 & 2475792 & 64640 \\
\hline \multirow{2}{*}{$\begin{array}{l}\text { Neura } \\
1 \\
\text { Netw } \\
\text { ork }\end{array}$} & RMS & 0.0178 & 0.029208 & 0.02510 & 0.0107 \\
\hline & $\begin{array}{l}\text { Estimat } \\
\text { ed Cost }\end{array}$ & 84425 & 1313315 & 2333379 & 71538 \\
\hline
\end{tabular}

B stands for Building, M stands for Mezzanine, T stands for Total

The table shows that for the four experiments A, B, C, and $\mathrm{D}$ the estimated cost enhances the value of the closest match cost. The deviation of the estimated cost from the actual cost is acceptable in the range of the hundred thousands Saudi Reyals (the currency used in Zamil Steel database). This is also applicable for experiment $\mathrm{E}$ in the two sub-systems.

Note that the cost is measured here in Saudi Reyals. One may say that if the projects in the available case-base are captured two years ago, these figures should give incorrect prices. This is correct if the stored cost is the actual cost, but the stored cost here is the price book cost. Large contracting companies often calculate the cost of their projects by using the price book system. Price book is a book that contains prices for every item used in the project as well as an equation to calculate it after certain number of years. So, the prices included in this book are considered constant prices. However, companies never sell their buildings using the prices obtained form the price book directly because they are too high in order to ensure steady state. Yet, they have to give their customers a discount over these prices according to the market status. The results in this paper give the price book cost of the building. Sales engineers have to apply an appropriate discount to the output price.

\section{System Verification \& Results Evaluation}

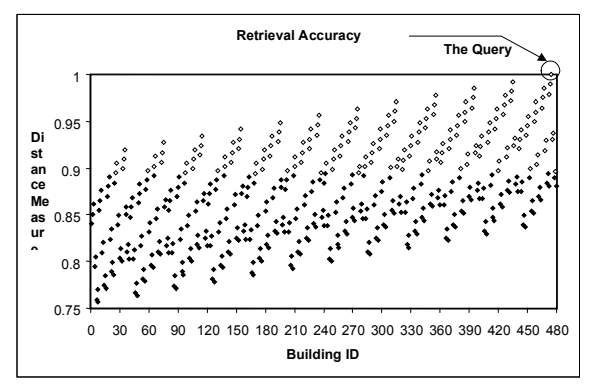

Fioure 4 I noical Validity of the CRR

\subsection{Check Retrieval Accuracy}

A case should exactly match itself. This means that if the case-base is queried with one of its cases, it should gives 
the same case with distance measure equals $100 \%$. This is shown in Figure 4. The only case hits the value 1.0 is the query case. If a case does not retrieve itself or does not match exactly, there is something wrong in the retrieval algorithm (Watson, 1996).

\subsection{Check Retrieval Consistency}

If exactly the same search has been performed twice, the same source cases should be retrieved with the same accuracy. If this does not happen, then there is something wrong with the retrieval algorithm (Watson, 1996).

\subsubsection{Check for Case Duplication}

A case should exactly match itself, but should not be identical to other cases. Duplicate cases will not harm decision making but may slow the system down or cause other administrative problems (Watson, 1996). This is clearly shown in Figure 4. There is one just case that matches itself.

\subsubsection{Check Case Coverage}

To check the case coverage, the standard deviation of the numerical features should be as low as possible. The mean of the feature value should also be near to middle of the feature range (Watson, 1996). Error! Reference source not found. illustrates the standard deviation (SD), mean, median of the some different numerical features of the building. The SD of the 'Width' and 'Length' seem to be high with respect to that of the ' Height'. The reason is the 'Width' feature ranges from 15.00 to 80.00 meters and the 'Length' ranges from 30.00 to 120.00 meters while the 'Height' ranges from 6.00 to 12.00 meters. This is also applicable for 'Bay Spacing'. The table shows that the median and the mean of the features are so close.

\subsection{Global System Verification Tests}

The steps described above have all concentrated on individual aspects of a CBR system and its performance, retrieval accuracy, consistency, and case coverage that undoubtedly affects the system's performance. However, it is also vitally important to verify the overall performance of the system. The steps of this test are as follows (Watson, 1996):

- Did the system retrieve a useful set of cases?

- Was the retrieval time acceptable?

- Was the adaptation successful?

Table 4 has the answer of the above questions.

Table 4: Global System Verification Check

\begin{tabular}{|l|l|l|l|}
\hline Experiments & A & B & C \\
\hline
\end{tabular}

\begin{tabular}{|l|l|l|l|l|l|}
\hline Building & Cost & $\begin{array}{l}89329 \\
3\end{array}$ & $\begin{array}{l}13639 \\
00\end{array}$ & $\begin{array}{l}24023 \\
80\end{array}$ & $\begin{array}{l}74464 \\
8\end{array}$ \\
\hline Retrieval & $\begin{array}{l}\text { Retriev } \\
\text { ed Cost }\end{array}$ & $\begin{array}{l}75693 \\
\text { Adaptation }\end{array}$ & $\begin{array}{l}14211 \\
48\end{array}$ & $\begin{array}{l}24757 \\
92\end{array}$ & $\begin{array}{l}64640 \\
1\end{array}$ \\
\hline \multirow{2}{*}{$\begin{array}{l}\text { Estimat } \\
\text { ed Cost }\end{array}$} & $\begin{array}{l}84425 \\
8\end{array}$ & $\begin{array}{l}13133 \\
15\end{array}$ & $\begin{array}{l}23333 \\
79\end{array}$ & $\begin{array}{l}71538 \\
7\end{array}$ \\
\hline & $\begin{array}{l}\text { Retriev } \\
\text { ed/ } \\
\text { Origina } \\
1\end{array}$ & 84.7 & 104 & 103 & 86 \\
\cline { 2 - 6 } & $\begin{array}{l}\text { Adapte } \\
\mathrm{d} / \\
\text { Origina } \\
1\end{array}$ & 94.5 & 96 & 97 & 96 \\
\hline
\end{tabular}

From the above table the answer to the first question is yes. It is clear that retrieved closest match case is close to the source case. In some experiments, it is very close. The answer of the second question is not more than 3 seconds. All the retrieval experiments take about 3 seconds to get all cases sorted according their distance measure. The answer to the third question is also yes. The adaptation results are clearly very good. The estimated building cost is close to the original building with a range of $4 \%$. In the manual estimation process, there is over estimation up to $10 \%$ of the building, this percent will cover the $4 \%$ difference of the estimated cost.

In conclusion, after all the experiments, the system is successful in getting a correct estimation of the five buildings. This proves the concept of applying neural networks in case-based reasoning adaptation.

\section{Conclusion}

A new technique in case-based reasoning adaptation is successfully developed. The technique applies neural computing in the most difficult part of the CBR process, which is case adaptation. The application of the new technique is done within a real world problem that faces a lot of contracting companies, which is the cost estimation of Pre-Engineered steel buildings.

Several experiments are conducted to prove that these steps are successful. Both un-decomposed and decomposed CBR experiments were conducted. The system was successful in getting correct estimation to five different queries (the last one was decomposed CBR testing). The system was verified by conducting several tests in order to measure retrieval accuracy, retrieval consistency, case duplication, case coverage, and the overall system performance. System verification shows that both the system and the methodology are successful 
to develop a complete complex adaptation mechanism in CBR.

\section{References}

Aamodt, A., \& Plaza, E. (1994). Case-Based Reasoning: Foundational Issues, Methodological Variation and System Approaches. AICOM, Vol.7, No.1.

Abd Rabou, E. A. (1999). Applying Neural Networks in CaseBased Reasoning Adaptation for Cost Assessment of Steel Buildings. Ms.C. Thesis submitted to the American University in Cairo, School of Science and Engineering.

Achofiled, C. \& Shepperd, M. (1995). Software Support for Cost Estimation by Analogy. ESCOM 6, Rolduc. Available: http://dec.bournemouth.ac.uk/ dec_ind/decind22/web/ESCOM95.html

Aha, D. W., \& Ram, A. (1995). Adaptation of Knowledge for Reuse. Papers from the 1995 Fall Symposium. California: The AAAI Press.

Bonzano, A. (1998). ISAC: a CBR system for decision support in air traffic control. Ph.D. Thesis submitted to the University of Dublin, Trinity College.

Booch, G. (1994). Object-oriented analysis and design. Redwood City, CA: The Benjamin/ Cummings Publishing Company, Inc.

Carnahan, B., \& Smith, A. E. (1997). Pittnet [Computer Software, Free Copy]. Department of Industrial Engineering, University of Pittsburgh.

Carnahan, B., \& Smith, A. E. (1997). User's Guide to Pittnet Neural Network Educational Software. Department of Industrial Engineering, University of Pittsburgh.

Chester, D. (1990). Why two hidden layers are better than one. Proceedings of the International Joint Conference on Neural Networks. Washington, D.C., Neural Network Society.

Cunningham, P., \& Symth, B., \& Bonzano, A. (1998). An Incremental Retrieval Mechanism for Case-Based Electronic Fault Diagnosis. Knowledge-Based Systems Journal, Jan.

Daniel, R., \& James, H., \& Garret, J. (1991). Neural computing for intelligent structural systems. Proceedings of the International Workshop on Intelligent Systems.

Danon (1995). WinNN, 0.97 [Computer Software, Registered Copy].

DTI NeuroComputing Web, (1993). [On-line], Available: http://www.clients.globalweb.co.uk/nctt/guide/

Durkin, J. (1994). Expert systems design and development. New York: Macmillan Publishing Company.

Flemming, U. \& Coyne, R. \& Snyder, J. (1993). SEED: A Software Environment to Support the Early Phases in Building Design. In ARECDAO93 Proc. IV Int. Conf. On Computer Aided Design in Architecture and Civil Engineering. Barcelona, Spain.

Gebhardt, F., \& Vob, A., \& Grather, W., \& Schmidt-Belz, B. (1997). Reasoning with Complex Cases. Boston: Kluwer Academic Publishers.
Hammond, K. (1986). CHEF: A model of case-based planning. In Proceedings of AAAI-86. Cambridge, MA: AAAI Press/MIT Press.

Hegazy, T. \& Fazio, P. \& Moselhi, O. (1994). Developing practical neural network applications using backpropagation. Microcomputers in Civil Engineering. Vol. 9.

Hegazy, T. \& Moselhi, O. (1994). Analogy-Based Solution to Markup Estimation Problem. Journal of Computing in Civil Engineering. Vol. 8, No. 1.

Hinrichs, T. R. (1992). Problem solving in open worlds: A case study in design. Northvale, NJ: Erlbaum.

Kolodner, J. L. (1993). Case-Based Reasoning, California: Morgan Kaufmann Publishers.

Koton, P. (1988). Integrating case-based and causal reasoning. In Proceeding of the Tenth annual Conference of the Cognitive Science Society. Northvale, NJ:Erlbaum.

Kriegsman, M. \& Barletta, I. R. (1993). Building a CaseBased Help Desk Application. IEEE Expert, 8(6).

Leake, D. B. (1995). Combining rules and cases to learn case adaptation. Proceeding of the Seventeenth Annual Conference of the Cognitive Science Society.

Leake, D. B. (1996). Case-based reasoning: experiences, lessons, and future directions. Menlo Park: AAAI Press/ MIT Press.

Li, H. (1995). Neural Network Based Cost Estimation Model. System Design. Journal of Australian Institute of Building Papers.

Li, H. (1995). Neural Network Models for Intelligent Support of Mark-Up Estimation. International Journal of Engineering Construction Management.

Maher, M. \& Gomez de Silva Garza, A. (1996). Design case adaptation using genetic algorithms. Computing in Civil Engineering. American Society of Civil Engineering.

Maher, M. \& Gomez de Silva Garza, A. (1996). Developing case-based reasoning for structural design. IEEE Expert, 11(3).

Maher, M. \& Gomez de Silva Garza, A. (1996). The adaptation of structural system designs using genetic algorithms. Proceedings of the International Conference on Information Technology in Civil and Structural Engineering Design —Taking Stock and Future Dir.

Manago, M. \& Bergmann, R. \& et. al. (1994). CASUEL: a common case representation language. ESPRIT project 6322,Task 1.1, Deliverable D1. Available FTP: ftp://ftpagr.informatik.unikl.de/pub/CASUEL/Documentation/Casuel2.01.ps.gz

Moselhi, O. \& Hegazy, T. (1993). DBID: Analogy-Based DSS for Bidding in Construction. Journal of Construction Engineering and Management, Vol. 119, No. 3.

Pao, Y. H. (1989). Adaptive pattern recognition and neural networks. Reading, Ma: Addison Wesley.

Polyak, B.T. (1964). Some methods of speeding up the convergence of iteration methods. Z. Vycisl. Mat. i Mat. Fiz., 4.

Purvis, L.\& Pu, P. (1995). Adaptation using constraint satisfaction techniques. In Veloso, M. \& Asmodt, A. (eds) 
Topics in Case Based Reasoning, Proceedings of the First International Conference on Case Based Reasoning, LNAI Series. Springer Verlag.

Reategui, E. \& Campbell, J. A. \& Borghetti, S. (1995). Using a neural network to learn general knowledge in a casebased system. Case-Based Reasoning Research and Development.

Rich, E. \& Knight, K. (1991). Artificial Intelligence $2^{\text {nd }}$ Edition. New York: McGraw-Hill, Inc.

Riesbeck, C. K., \& Schank, R. C. (1989). Inside case-based reasoning. Hillsdale, New Jersey: Lawrence Erlbaum Associates Publishers.

Rose 98 (1998). Rational Rose 98. [Computer Software, Evaluation Copy].

Rumelhart, D.E., Hinton, G.E., and Williams, R.J. (1986). Learning internal representations by error propagation. Rumelhart, D.E. and McClelland, J. L., eds. (1986). Parallel Distributed Processing: Explorations in the Microstructure of Cognition. Vol. 1, 318-362, Cambridge, MA: The MIT Press.

TECHINNO (1995). CBR-Works [Computer Software, Evaluation Copy].

Tsatsoulis, C. \& Change, Q. \& Wei, H. (1997). Integrating case-based reasoning and decision theory. IEEE Expert, 11(4).

Watson, I. (1994). The Case for Case-Based Reasoning, Proceedings of EPSRC/DRAL, November 1994.

Watson, I. (1997). Applying Case-Based Reasoning: Techniques for Enterprise Systems. California: Morgan Kaufmann Publishers.

White, I. (1994). Using the Booch Method: A Rational Approach. California: The Benjamin/ Cummings Publishing Company, Inc.

Zamil Steel (1997). Product Brochure: Pre-Engineered Buildings. Zamil Steel Building Co. LTD.

Zamil Steel (1998). Technical Manual: Pre-Engineered Buildings. Zamil Steel Building Co. LTD. 